\title{
ŽUPA KRIVI PUT
}

\author{
Mile BOGOVIĆ \\ Gospićko-senjska biskupija \\ Senjskih žrtava 36, 53000 Gospić
}

$\mathrm{N}$ a prostranom području današnje župe i Mjesnog odbora Krivi Put iz srednjega nam je vijeka poznat lokalitet Vlaška Draga, u kojoj je 1390. godine senjski arhiđakon Radovan dao sagraditi pavlinima samostan i crkvu sv. Jelene (Bogović 1988:109-120). Pavlini su ondje ostali negdje do dvadesetih godina 16. stoljeća, kada su zbog čestih turskih pljački morali potražiti sigurnije sklonište. Samostan nije poslije obnavljan. Od zidova crkve još je dosta ostalo, a vide se i temelji samostana. Fratri sv. Jelene imali su preko brda svoje posjede, na što upućuje naziv Vrataruša. 20. ožujka 1461. godine darovala im je kneginja Elizabeta Frankopanka sjenokošu u Dolcu (Šurmin 1899:227-228). ${ }^{1}$ Senjski franjevci (franciskani) imali su posjede iznad Senja, otkuda naziv Francikovac. Neki smatraju da je u Francikovcu u srednjem vijeku bila benediktinska opatija sv. Dujma. ${ }^{2}$

Spomenuti naziv Vlaška Draga govori o tome da su i u ono vrijeme te krajeve nastavali stočari, potomci romaniziranih stanovnika rimskoga Ilirika, obično nazivani Vlasima. Oni su, dakako, svi bili katolici i već odavno pohrvaćeni. Vlaški korijen ima i naselje Veljun (vallis, valun, veljun - udolina, draga).

\section{NASELJAVANJE BUNJEVACA}

Gav taj prostor postao je nesigurno boravište u vrijeme kada su se Turci zalijetali do mora, pa možemo

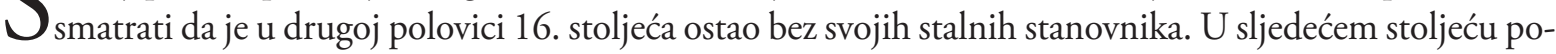
čet će ga naseljavati novi stočari, poznati pod imenom Bunjevci (Pavičić 1962, 1966:309-382), ${ }^{3}$ koji su se sa svojim stadima ljeti povlačili u unutrašnjost, a zimi spuštali prema moru. Kao stočari bili su pokretljivi te su tako mogli opstati oko turske granice povlačeći se sa svojim stadima na sigurnija pasišta. Stabilna seljačka domaćinstva nisu se u tim prilikama mogla na tom prostoru održati. I kada su naišli na sigurnija područja, još dugo su se sa svojim stadima kretali, ali su se ipak malo po malo vezivali uz određeni grunt. Sve do 20. stoljeća mnogi će od Bunjevaca na krivoputskome području ljetovati u unutrašnjosti, a zimovati uz more.

U vrijeme vizitacije biskupa Glavinića 1695. godine Bunjevci Krmpoćani imaju svoju župnu crkvu sv. Jakova. Po tim će se Krmpoćanima mjesto poslije prozvati Krmpote. Biskup Pohmajević spominje 1727. godine na tom području 80 bunjevačkih kuća. On je na blagdan zaštitnika župe, sv. Jakova, 25. srpnja posvetio župnu crkvu. U vrijeme njegove vizitacije ne spominje se crkva u Krivome Putu. Biskup Benzoni godine 1733. piše da bi trebalo sagraditi crkvu na području Malića kako bi se Bunjevci mogli i ljeti okupljati na misu i pouku. Tada već u Podbilu postoji proštenjarska crkvica Majke Božje Snježne, za koju biskup kaže da je u dobrom stanju jer je gotovo sagrađena.

Predaja kaže da je ondje pao snijeg 5. kolovoza što je shvaćeno kao želja Majke Božje da joj se na tom mjestu sagradi crkva (takva predaja je i u počecima nastanka crkve sv. Marije Velike u Rimu).

Nedaleko od Vrataruše nalazi se Butković dolac. Vjerojatno je riječ o tom lokalitetu.

2 Više o crkvenim redovima na području Krivoga Puta u radovima M. Bogovića u Senjskom zborniku 15 (1988) i 17 (1990).

3 Opsežan prilog poznavanju naseljavanja Bunjevaca je knjiga Stjepana Pavičića: Seobe i naselja u Lici. Isti je autor u Senjskom zborniku 2 objavio i članak, posvećen uglavnom problematici raseljavanja i naseljavanja. Tu je opširnije dotaknuto i naseljavanje Krivoga Puta. 


\section{OSNUTAK ŽUPE}

$\mathrm{V}$

eć je u 18. stoljeću u krivoputskim krajevima bilo dosta stanovništva sa stalnim boravkom. Biskup Čolić bilježi da je godine 1747. spomenuta crkva Gospe Snježne povjerena krmpotskom kapelanu

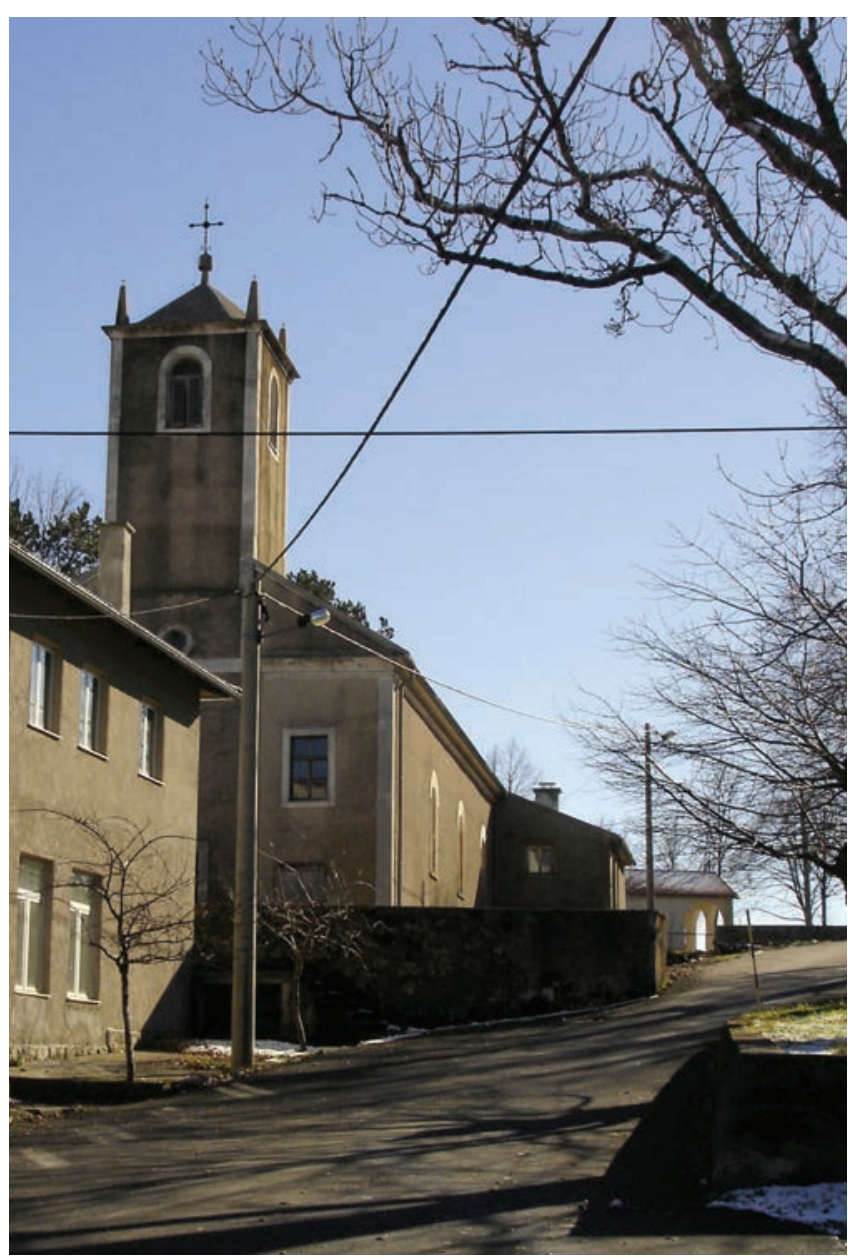

Slike 1: Crkva Majke Božje Snježne; snimio Augustin Perić, studeni 2007. godine i Podbilaru Antunu Tomljanoviću zvanom Panjić, a senjski vikar Vinko Vukasović 1756. godine predlaže da se ondje osnuje samostalna kapelanija. Koncem tog stoljeća krivoputski je kraj bio napučeniji od krmpotskoga, zato je službena vladina komisija 1789. godine odlučila da se središte župe premjesti u crkvu Majke Božje Snježne. Odredba je provedena naredne godine. Tako je Krivi Put postao župsko središte, a Krmpote su postale krivoputska kapelanija. Ta će se kapelanija 1807. godine osamostaliti u posebnu župu. Od tada se župske granice nisu mijenjale. Kada je osnovana krivoputska župa, pripojena su joj naselja Veljun i Francikovac, koja su do tada bila pod župom Senjska Draga. ${ }^{4}$

Prijašnja crkva Gospe Snježne nije bila dovoljno velika, pa je već 1790 . započeta gradnja nove (sl. 1). Godine 1794. sagrađen je i župni stan.

\section{NAGLI RAZVOJ I JOŠ NAGLIJE OPADANJE}

U 19. je stoljeću broj stanovnika zbog prirodnog priraštaja neprestano rastao te je 1856. godine sagrađena veća i potpuno nova crkva, kako svjedoči ploča na njezinu pročelju. To je već treća crkva na istom mjestu. Crkva se razvila u hodočasničko središte za okolne župe, a dolazili su i hodočasnici s otoka (Sladović, 1856:251). Papa Lav XIII. je 1892. godine dodijelio crkvi za blagdan Gospe Snježne povlasticu potpunog oproštenja pod uobičajenim uvjetima. ${ }^{5}$ To je još više privuklo pobožne hodočasnike.

Porastom stanovništva i ta se crkva pokazala premalenom. Godine 1910. srušeno je staro svetište crkve i na tome je mjestu ona produljena za cijelo današnje svetište i za nekoliko metara lađe. Biskup Ivan Starčević posvetio je 5. kolovoza 1934. godine (na župski blagdan) novi oltar, djelo G. Repara (Istina 1934: 32,

\footnotetext{
Vratnik je postao župom tek 1807. godine.

5 Biskupski arhiv u Senju, Podaci o župama, R 31.
} 
4; 33,4). Slika na njemu uzeta je sa starog oltara, a nabavljena je godine 1881 . Bila su to vremena kada su obitelji u prosjeku imale desetak djece, a nisu bili rijetki ni slučajevi s dvadesetero. Budući da svi nisu mogli ostati na gruntu, mnogi su se iselili, a od onih koji su ostali, jedni su radili kod kuće, a drugi su tražili posao u bližim i daljim gradovima. Prva glavna stanica bio je Senj, druga Zagreb, a mnogi otiđoše i preko mora. Preostali su se ženidbama i udajama tako povezali da su gotovo svi međusobno po nekoj liniji rodbina.

Do posljednjeg rata bila je stalno prisutna potreba da se crkva proširuje, a nakon toga postajala je ona previše prostrana za ljude koji u nju dolaze. Kad bi se mogla umanjivati, bila bi dovoljna onakva kakvu bunjevački pastiri sagradiše oko 1730. godine, onda kada se proširio glas da je na jednom mjestu pokraj Podbila snijeg pao 5. kolovoza i da Majka Božja želi da joj se na tome mjestu sagradi crkva.

Prema biskupijskim shematizmima bilježimo sljedeće kretanje stanovništva:

$1827 .-1634$
$1837 .-2056$

Godine 1862. spominje se nedaleko od župne crkve i kapelica Mile Prpića.

Blagdan Gospe Snježne bio je i ostao glavno godišnje okupljalište Krivopućana i onih s područja župe i onih koji su nekamo odselili (sl.2). Mnogi iz udaljenih krajeva imaju u planu svake godine putovanje/ hodočašće Gospi Snježnoj (sl.3).

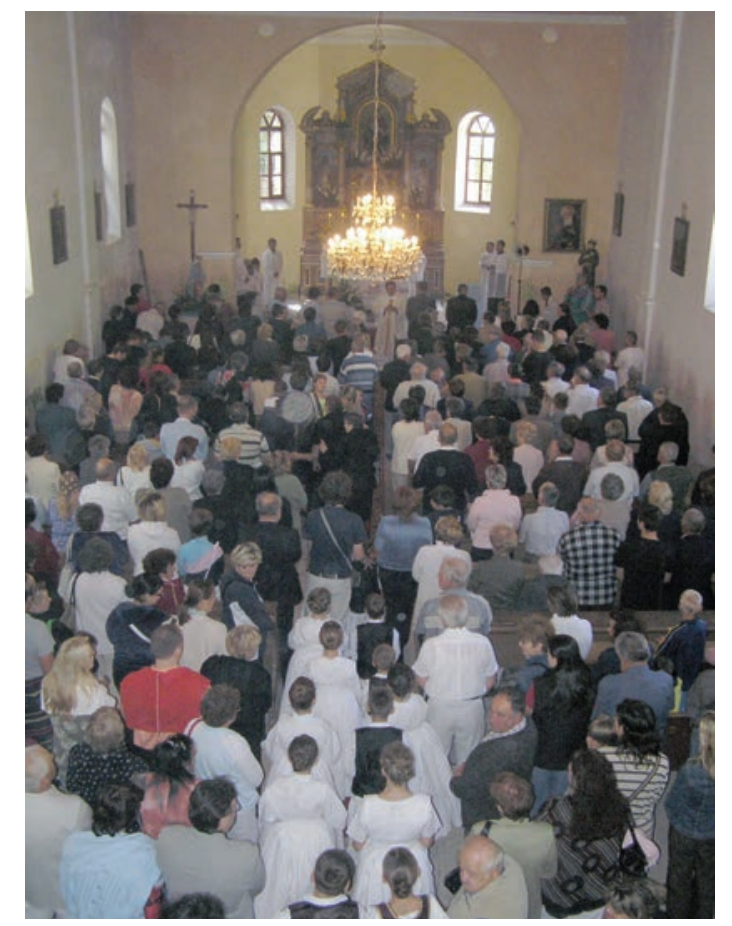

Slika 2: Bogoslư̆je 5. kolovoza 2006. godine u crkvi Majke Bơ̌je Snježne; snimila Marijeta Rajković

6 Prema popisu iz 1991. bilo je u krivoputskim naseljima (Alan, Krivi Put, Mrzli Dol, Podbilo, Veljun Primorski, Vrataruša) popisano 483 građana. Tu su pribrojeni i stanovnici uz more koji pravno pripadaju Krivome Putu, ali s njima imaju slabe veze. Po svoj prilici oni nisu ubrojeni u gore navedenih 200 stanovnika. 


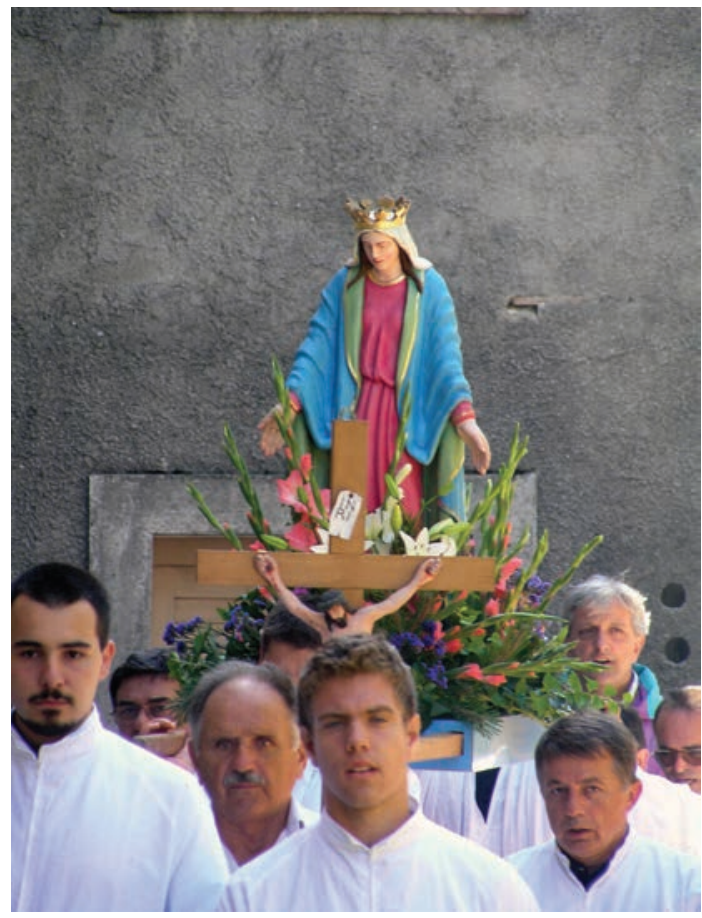

Slika 3: Procesija s kipom Majke Bơ̌je Snježne 5. kolovoẓa 2006. godine; snimila Marijeta Rajković

Pjesnik Milan Pavelić, Krivopućanin, preporučivao je da se sagradi nova župna crkva u naselju Krivi Put (kod Kumpanije) jer je inače župna crkva na osami. U Krivome Putu bila bi bliža većini župljana. Inače župa je tridesetih godina prošloga stoljeća spadala među uglednije župe u biskupiji. Osnovana su ondje razna katolička društva. Tako je 1934. godine osnovano djevojačko društvo i društvo Srca Isusova. ${ }^{7}$

Mnogo je župljana stradalo u Drugome svjetskom ratu. Iseljavanje i pad nataliteta doveli su do nagla demografskog pada. Osim toga, župnik je boravio izvan župe. Nije više bilo snage za nove inicijative, nego je trebalo kako tako održavati preostalo. Godine 1964. promijenjen je krov na crkvi, a za vrijeme župnika Galovića (1973.-1985.) dograđen je nad sakristijom mali župni stan.

Krivoputski župnici i upravitelji župe: ${ }^{8}$

Juraj Biličić

Grga Pilaš

Antun Škiljan

Stjepan Antonić

Dragutin Vranić

Ivan Žanić

Vinko Šegulja
1795 ? $^{9}$

1806.

1827.

Šimun Srdoč

Konrad Modrčin

Petar Mažuranić

Rikard Valić

Josip Gurzan

1837. i 1845.

1860.-1864.

1864.-1871.
Feliks Šeliga

Vilko Veber

Dr. Antun Lončarić
1871.-1888.

1890.-1896.

1896.-1933.

1934.-1938.

1938.-1939.

1939. $-1942 . .^{10}$

1943.-1944.

1945. $(-1956 .)^{11}$

Biskupski arhiv Senja, spisi 1934. br. 775 i 949.

8 Za prve navodim kada sam ih našao u spisima, ali nije poznato koliko su župnikovali.

9 Prvim župnikom je trebao biti Joakim Stauber, bivši pavlin, ali se on nije dao premjestiti iz Cvitovića u Krivi Put. Dana 13. svibnja 1792. moli on biskupa da ga se ne sili na premještaj (Biskupski arhiv Senj, kutija IX, br. 48.)

10 Nakon što je uništen župni stan, Šeliga je otišao u Slovačku otkuda je rodom. Poslije toga župnici nisu više stanovali na Krivome Putu osim Lončarića koji je bio nastanjen u kući kraj crkve.

11 Antun Lončarić je kao senjski župnik bio saborski zastupnik za vrijeme NDH. Nakon 1945. godine prognan je na Krivi Put. Boravio je u kući Anke Šolić pokraj crkve jer je župni stan 1942. godine bio zapaljen i srušen. Ispod ulaznih stepenica skrivao se do 1948. godine Ankin sin Mićo, a u kući je imala svoju postaju i milicija. Često je bio sprječavan u obavljanju svećeničkih dužnosti. Od 1950. do 1952. pomagao mu je dr. Ljubomir Kučan, biskupijski kancelar iz 


$\begin{array}{llll}\text { Dr. Adalbert Ježić } & 1952 .-1954 . & \text { Mile Bogović } & 1964 .-1965 . \\ \text { Ivan Čeperić } & 1954 .-1959 . & \text { Nikola Žuravelj } & 1965 .-1973 .{ }^{12} \\ \text { Albin Kordić } & 1959 .-1960 . & \text { Marijan Galović } & 1973 .-1985 . \\ \text { Nikola Žuravelj } & 1960 .-1961 . & \text { Mile Bogović } & 1985 .-1986 .{ }^{13} \\ \text { Mijo Liković } & 1961 .-1963 . & \text { Tomislav Šporčić } & 1986 .-1993 . \\ \text { Josip Jurković } & 1963 .-1964 . & \text { Mile Čančar } & 1993 .-\end{array}$

Povijest krivoputske crkve i župe bila je tijesno vezana uz povijest ljudi koji ondje žive. Dugo se vremena nastojalo odvojiti jedno od drugoga; valjda je i tome došao kraj. ${ }^{14}$

\section{TUŽALJKA NAD KRIVIM PUTEM ${ }^{15}$}

$\mathrm{P}$ isac ovih redaka došao je već kao mladomisnik za upravitelja župe Krivi Put. Tu je bio samo jednu radnu godinu. Prođoše mnoge godine i opet se nađe u Krivome Putu. U ovo nekoliko redaka želi iznijeti dojmove nakon što se po drugi put susreo s Krivim Putem, posebice nakon što je prigodom blagoslova kuća susreo preostale ljude u tom naselju.

Gledajući Krivi Put nakon dvadeset i koju godinu, on se veoma izmijenio. Prije je bila po koja prazna kuća. Sada se može reći da još ima nešto kuća u kojima netko živi. Već onda je iseljavanje bilo u tijeku i mnogi su svoj daljnji boravak u Krivome Putu shvaćali kao pripremu za putovanje u Senj ili koji drugi grad. Krivi Put izgledao je kao brod koji se počeo nakretati, a ljudi gledaju kako bi do obale i kojim će se čamcem za spašavanje prebaciti. Ali tada je bilo i onih koji su vjerovali da se kvar na brodu može popraviti i nastaviti s plovidbom. No te rijetke optimiste izgleda da je vrijeme opovrglo.

To naglo bježanje s Krivoga Puta započelo je nakon nešto više od 300 godina kako su se ondje naselili Bunjevci. Prvi dođoše Krmpoćani (Krmpotići), a potom stigoše Prpići, Tomljanovići, Pavelići, Šojati, Vukelići i druga manje brojna prezimena. Uzgajali su krupnu i sitnu stoku i pomalo se bavili poljodjelstvom. Odgajani su u blizini granice između turskog i kršćanskog gospodara - koji put s jedne, a koji put s druge

Senja, a sljedeće dvije godine činio je to profesor na senjskoj gimnaziji dr. Adalbert Ježić (1952.-1954.). U prvo je vrijeme i Ivan Čeperić pomagao bolesnom Lončariću, a nakon njega preuzeo samostalno upravu. Stan je imao u Senju na Travici (Nehajeva ul. 3). Poslije će ondje stanovati i drugi upravitelji župe sve do uključivo Mile Bogovića (1965). Svećenici koji su upravljali župom iz Senja imali su zaduženja i u senjskoj župi (kapelani).

12 Žuravelj je bio imenovan župnikom na Vratniku otkuda je upravljao Krivim Putem i Senjskom Dragom. To isto vrijedi za njegova nasljednika Marijana Galovića.

13 Bogović je 1985. privremeno preuzeo upravu župe Senj, nakon smrti župnika Josipa Frkovića, i ujedno je upravljao župom Krivi Put. On je došao u Senj da preuzme upravu Sakralne baštine. I dalje je ostao profesor na Visokoj bogoslovskoj školi u Rijeci. Od 1985. godine pa do danas senjski župnici vrše i službu upravitelja župe Krivi Put.

14 Više o suvremenom pogledu na župu i naselje u Zvonima 1987/2, str. 7, naslov: Tužaljka nad Krivim Putem ili umiranje našega sela.

15 U ljeto 1964. imenovan sam senjskim kapelanom i upraviteljem župe Krivi Put. Stanovao sam u Senju na Travici. Na Krivi Put išao sam redovno samo za nedjeljnu misu u 11 sati i za sprovode. Na početku je trebalo ići češće jer je upravo te godine crkva popravljana. Autobus (Krivopućani su ga zvali „pruga“) išao je svakim danom, osim nedjelje, u 14.15 i došavši do okretišta u Krivome Putu vraćao se natrag u Senj. Kome je bilo nepogodno to vrijeme, išao je pješke. Tako sam i ja više pješačio nego se vozio. Kad bih došao subotom, pomeo bih crkvu i prespavao u sakristiji. Gotovo redovito sam uvečer navraćao kod bolesne Mare Prpić i njezine djece: Blaženke (13), Đure (11) i Marije (3). Muž Jure najčešće je bio negdje na terenskom poslu. Mara je uskoro umrla, ostavivši mi neizbrisiv primjer i uzor kako se treba nositi s križem i patnjom. Nakon nedjeljne mise redovito sam išao pješice u Senj. Prethodno sam ručao kod obitelji Danice i Miće Šolić. Nakon svega godine dana biskup dr. Viktor Burić slao me u Rim na daljnje studije. Budući da nisam dobio putovnicu („zbog veza s inozemstvom“!), godinu dana studirao sam u Zagrebu. Tada sam dobio putovnicu i otišao u Rim. U Senj sam se vratio 1985 . i otuda odlazio više puta u Krivi Put. Sada više nije trebalo ići pješke. O Božiću i Novoj godini 1986./87. obišao sam u blagoslovu kuća sve što je ostalo u župi Krivi Put. U ovoj crtici iznosim svoja zapažanja i svoje dojmove. 
strane. Mnogi su ginuli, ali ih se kudikamo više rađalo pa su mogli naseljavati i druge krajeve. Samo je tako žilavima i otpornima na sve nedaće pripadala budućnost. Te osobine i sličan način života sačuvali su oni do sredine 20. stoljeća. Iseljavanja su bila česta, ali se zavičaj nije prorjeđivao; između dva rata znalo ih je na krivoputskom području biti do 6000 . A kad bi se tom broju dodali i oni koji su otišli u svijet?!

Ali tada - kao da je netko kakvim zaraznim virusom poškropio iz visina sav taj kraj.

Prije ovoga Božića bio je jedan sprovod, pa sam mogao obavijestiti kada će biti misa na Božić, a za Božić sam namjeravao reći raspored posjeta obiteljima ili blagoslova kuća. Ali na Božić nije bilo nikoga u crkvi. Zapjevao sam jednu božićnu pjesmu i zaključao crkvu. Već sutradan počeo sam iznenađivati ljude svojim posjetom. Vrijeme se proljepšalo, cesta čista, asfalt ne samo do svake kuće nego gotovo do svakog kokošinjca. Taj mi asfalt sada djeluje kao podmetnuta klizaljka koja omogućuje da i ono ljudi što je ostalo što prije klizne iz Krivoga Puta. Namjere graditelja, dakako, bile su mnogo plemenitije. Rekoše mi da u Vratarušu, Kosovu Buljmu, Šušanj i Butković Dolac ne trebam ni ići jer ondje nema više ni žive duše. Šojatski Dolac koji je 1915. godine imao 211 duša sada ih nije sačuvao ni 11. U Šolićima, mještanka Anka Tutanova pamti da je jedne godine bilo 17 udavača, a sada su ostali samo ona i muž invalid. Kada se penje blagu po sijeno uvijek misli što bi bilo kada bi pala i slomila nogu, tko bi od njih dvoje mogao kome pomoći. Bila bi također potrebna velika i dugotrajna kuknjava da te netko treći može čuti.

Nije ni svećeniku tu lako. Prolaziš kraj kuća, vičeš sad Hvaljen Bog!, sad Dobar dan!, a iza toga često ostaje samo prazan muk. Ako je kuća nastanjena, obično se prvi javi pas. Ipak je netko tu! Nekoji put je potrebno doći do samog kreveta da bi se sreo sa starijima i nemoćnima: Teško je biti bolestan, a ne vidjeti zdravu ruku kraj sebe, teško je biti star a ne imati mlado kraj sebe, teško je podnositi zimu kada ono što vani čuješ nisu ljudski koraci nego svirka vjetra i bure po ogoljelim granama i rasklimanom suvoću; kada otvoriš ujutro snijegom zametena vrata, nigdje ne možeš ugledati ljudske tragove. Drago ti je tada da pronadeš i trag kakve divljači. Nešto živo je ipak tuda prošlo!

Mogli bismo nizati tužaljku do tužaljke. Gorka je istina da od pet škola na krivoputskom području više nijedna ne radi. Krivi Put više neće naseljavati druge krajeve jer je i sam opustio. Biološka žilavost koja ga je 300 godina držala danas je slomljena.

I kada promatram taj nezaustavljivi hod, uhvati me neka sjeta, pogotovo kad su brojne lijepe uspomene vezane uz to što nestaje.

Još je tužnije što to nije usamljeni slučaj. Sve više naših sela kreće istim putem. Od 25 osnovnih škola koje su u nedalekoj prošlosti djelovale u senjskoj općini ostale su još samo četiri. 1 dođe čovjeku želja da se popne na najviše brdo i da na sve strane počne vikati: Ljudi, to je krivi put! Ali znam da bi i najmanji vjetrić mogao oduzeti snagu tome glasu, a naše bi selo svejedno išlo onim putem kojim je već odavno krenuo Krivi Put.

\section{IZVORI}

Biskupski arhiv u Senju, Podaci o župama, R 31.

Biskupski arhiv Senj, kutija IX, br. 48.

Biskupski arhiv Senja, spisi 1934., br. 775 i 949.

\section{LITERATURA}

BOGOVIĆ, Mile (1988): Pavlini u Senju. Senjski zbornik, 15:109-120, Senj.

Istina (1934.): I, 32, 4; 33, 4.

PAVIČIĆ, Stjepan (1962): Seobe i naselja u Lici. Zbornik za narodni život i običaje JAZU knj. 41, Zagreb. 
PAVIČIĆ, Stjepan (1966): Prilozi nepoznatoj prošlosti grada Senja i okolice. Senjski zbornik, 2:309-382 Senj.

ŠURMIN, Gjuro (1899): Hrvatski spomenici. Zagreb.

SLADOVIĆ, Manojlo (1856): Povesti biskupijah senjske i modruške ili krbavske. Trsat (pretisak Zagreb Gospić, 2003). 